\title{
Biosorption of heavy metals by Talaromyces helicus: a trained fungus for copper and biphenyl detoxification
}

M. Cristina Romero*

Micología Médica e Industrial

Posgrado en Microbiología

Facultad de Ciencias Veterinarias

Universidad Nacional de La Plata

Av. 60 e/ 119 y 120 s/nro., 1900

La Plata, Argentina

Tel: 00542214250577

Fax: 00542214222904

E-mail: cmriar@yahoo.com.ar

\section{Enso H. Reinoso}

Micología Médica e Industrial

Posgrado en Microbiología

Facultad de Ciencias Veterinarias

Universidad Nacional de La Plata

Av. 60 e/ 119 y 120 s/nro., 1900

La Plata, Argentina

Tel: 00542214247642

E-mail: reinoso@fcv.unlp.edu.ar

\section{Inés Urrutia}

Facultad de Ciencias Agrarias y Forestales

Universidad Nacional de La Plata

Av. 60 e/ 119 y 120 s/nro., 1900

La Plata, Argentina

Tel: 00542214247642

Fax: 00542214222904

Tel: 00542214835934

E-mail: urrutia@isis.unlp.edu.ar

Alejandro Moreno Kiernan

Facultad de Ciencias Agrarias y Forestales

Universidad Nacional de La Plata

Av. 60 e/ 119 y 120 s/nro., 1900

La Plata, Argentina

Tel: 00542214247642

Fax: 00542214222904

Tel: 00542214250577

E-mail: cmriar@yahoo.com.ar

Financial support: This work was supported by grants from the National Council of Scientific and Technological Research (CONICET) and from the National University of La Plata (UNLP- Facultad de Ciencias Veterinarias), Argentina.

Keywords: biodegradation, biphenyl, cocontaminated sites, cotolerance, metal sorption, Talaromyces helicus.

Abbreviations: BP: biphenyl

DBF: dibenzofuran

MM: mineral medium

RF-HPLC: reverse phase

SEM: scanning electron microscopic

At present, it is common to observe environments with organic and inorganic pollution, defined as cocontamination. Most industrial and urban effluents releases both pollutant types, leading to a complex environmental problem, as the biota must be tolerant to both xenobiotics. $T$. helicus, an efficient strain to degrade biphenyl, was trained with high copper levels, and became co tolerant to cobalt, lead and cadmium

*Corresponding author 
when was cultured in their presence. The copper adaptation was the result of physiological mechanisms, and the activated biochemical processes conferred resistance to $\mathrm{Cu}^{2+}$ as well as to other heavy metals. Furthermore, the $\mathrm{Cu}^{2+}$ adaptation of the mycelium was also transferred to the spores, that removed twice as much copper from solution than those of the no trained parentals. Interestingly, metals combinations were less toxic than single ones, and co tolerance development indicated that the cellular mechanisms that conferred resistance were non-specific, so the micobiota isolated from co contaminated environments often exhibited resistance to more than one ions. These results emphasized the detoxification abilities of $T$. helicus and the adaptation to heavy metals and biarylic compounds. This data is significant for the environmental biotechnology, suggesting that such tolerance and co tolerance could be acquired in natural environments. So a simple bioremediation strategy could enhance the detoxification of these polluted areas, as the degrader organisms could be present.

Remediation of co-contaminated sites with organic and metallic pollutants is a complex problem, as the components must be differently treated, yet $55 \%$ of the hazardous waste sites are co-contaminated (Roane et al. 2001; Sandrin and Maier, 2003). Alternatively, the area may be capped to prevent metal-transporting, or to reduce metal-mobilization by anaerobiosis (Roane et al. 1996; Kong, 1998; Kamashwaran and Crawford, 2001), or organic matter and clay additions (Malakul et al. 1998; Jonioh et al. 1999; Neilson and Maier, 2001), or environmental pH-changes (Majumdar et al. 1999; Sandrin and Maier, 2002) that determine ions bioavailability and affect the biota (Zoumis et al. 2001).

In either case, metal removal or stabilization is likely to be the first step to detoxificate co-contaminated sites (Atlas and Unterman, 1999; Liu et al. 2001), as inorganic pollutants in the ionic forms inhibit remediation through interaction with enzymes directly involved in biodegradation (e.g. specific oxygenases) or in general metabolism, by binding to the enzymes sulfhydryl-groups (Nies, 1999).

Unfortunately, few studies provide information on the metal levels that decreased the biotransformation due to the wide range of reported concentrations, and to different experimental protocols ions bioavailability and toxicity (Ricart et al. 2004). Alternatively, geo-chemical modelling software predicted metal speciation as a function of $\mathrm{pH}$ and ionic strength, and at least three computational models were developed to assess the ions impact on organics detoxification (Jin and Bhattacharya, 1996; Nakamura and Sawada, 2000; Amor et al. 2001).

Therefore, the aims of this study were to assess: a) the physiological adaptation to $\mathrm{Cu}^{2+}$ in Talaromyces helicus cultures in BP presence, b) the transference of $\mathrm{Cu}^{2+}$ - tolerance from the mycelium to the spores and to confer this resistance to other heavy metals and c) to quantify the inhibitory effects of metals on the fungal transformation BP.

\section{MATERIALS AND METHODS}

\section{Fungal isolation and identification}

T. helicus was isolated from co-contaminated sludge of the East Channel, near the YPF-oil Refinery, La Plata, Argentina. Diluted sediments were plated on MM-BP (Romero et al. 2001) for the presence of biarylic degrading fungi by standard spread-plate methods, by triplicate. The species were purified by streaking repeatedly on the same medium, and the fungus was identified by colonies showing typical yellow reverse, by ascospores that were only delicately spinulose, and the shaped ascogonia around which thin antheridia coil tightly, soon grew into a large terminal coil from which the ascogonous hyphae originated, and SEM observation.

\section{Culture conditions and metabolites identification}

One-hundred $\mathrm{ml} \mathrm{MM}$ with $2 \%$ glucose was inoculated with mycelial plugs $(4 \mathrm{~mm} \varnothing)$ of the previous culture. After 3 days incubation at $30^{\circ} \mathrm{C}$, a sloop full was used as inoculum of $100 \mathrm{ml} \mathrm{MM-BP}$, and incubated at $30^{\circ} \mathrm{C}, 180 \mathrm{rpm}$. Controls with the fungus without $\mathrm{BP}$ and not inoculated flasks were made, by triplicate, and the standard deviations were no more than $10 \%$.

At different sampling periods, $1 \mathrm{ml}$ culture was centrifuged (5000 x g, $5 \mathrm{~min}$ ), and metabolites were analyzed in $100 \mu \mathrm{l}$ supernatant separated from the mycelium by centrifugation during $130 \mathrm{hrs}$, the supernatants were extracted twice with ethyl-acetate at $\mathrm{pH} 7$, and once again at $\mathrm{pH} 2$. The organic phases were dried over $\mathrm{Na}_{2} \mathrm{SO}_{4}$, and the solvent removed by evaporation. The obtained residues were dissolved in methanol. The mycelium was washed twice with $5 \mathrm{ml}$ methanol; the methanolic extract was dried over $\mathrm{Na}_{2} \mathrm{SO}_{4}$ and the solvent reduced to $1 \mathrm{ml}$ by evaporation. The three extracts were analyzed by RF-HPLC (Hammer and Schauer, 1997). The UV-visible absorption spectra of the degradation products were determined in a diode array detector HP 1040 (Hewlett Packard, Bad Homburg, Germany), and the BP-derivatives were identified by comparison with standard compounds.

\section{Heavy-metals training}

T. helicus grew on MM-BP and was trained to increasing $\mathrm{Cu}^{2+}$-levels by serial transfer every 3 days to medium with 200, 300, 400, 500 and $600 \mathrm{ppm} \mathrm{Cu}^{2+}$. The media were adjusted to $\mathrm{pH} 5$, as metals occurs as divalent cations at this $\mathrm{pH}$. Not-exposed strains grew on the same medium without $\mathrm{Cu}^{2+}$ (non-trained strain), all the assays were done by triplicate. 
Table 1. Copper removed by non- and trained $T$. helicus at different Cu levels.

\begin{tabular}{|c|c|c|}
\hline Cu added & \multicolumn{2}{|c|}{ Cu removed (\%, respect to added Cu) } \\
\hline (ppm) & non trained strains & Cu-trained strains \\
\hline 200 & 4.7 & 8.9 \\
\hline 300 & 9.4 & 17.9 \\
\hline 400 & 9.8 & 28.0 \\
\hline 500 & 8.5 & 39.5 \\
\hline 600 & 7.5 & 52.0 \\
\hline
\end{tabular}

Then, a second assay were performed, and non- and $\mathrm{Cu}^{2+}$ training biotypes (plugs: $4 \mathrm{~mm} ø$ ) were plated in MM-BP amended with 50 to $700 \mathrm{ppm} \mathrm{Cd}\left(\right.$ as $\left.\mathrm{CdCl}_{2} .5 \mathrm{H}_{2} \mathrm{O}\right)$, or 10 to $225 \mathrm{ppm} \mathrm{Co}\left(\right.$ as $\left.\mathrm{CoCl}_{2} .6 \mathrm{H}_{2} \mathrm{O}\right)$ or 50 to $800 \mathrm{ppm} \mathrm{Pb}($ as $\left.\mathrm{Pb}\left(\mathrm{NO}_{3}\right)_{2}\right)$. Metal tolerance was assessed by the mycelial extension and computing radial growth rates $\left(\mathrm{mm} \times \mathrm{day}^{-1}\right)$.

\section{Single-spore cultures}

To determine if the $\mathrm{Cu}^{2+}$-resistant of the mycelia could be transferred to their spores, one sporangium from non- and $\mathrm{Cu}$-trained fungus were suspended in distilled water and agitated to release the spores. The spore suspensions were serially diluted in distilled water, and the spores from no training biotypes were plated on agar-medium without $\mathrm{Cu}^{2+}$, and those from $\mathrm{Cu}^{2+}$-adapted strain on $50 \mathrm{ppm} \mathrm{Cu}^{2+}, \mathrm{a}$ no inhibitory levels.

After incubation at $27^{\circ} \mathrm{C}$ for $24 \mathrm{hrs}$, spores germinated and formed an hyphal mass; hyphal plugs were first transferred to fresh media with no inhibitory $\mathrm{Cu}^{2+}$-level, and then 100 to $600 \mathrm{ppm} \mathrm{Cu}$, and mycelial extensions were measured. The $\mathrm{Cu}^{2+}$-sorbed by mycelia in both treatments were determined by measuring the level of $\mathrm{Cu}^{2+}$-free in solution with a selective electrode.

\section{Statistics}

Three replicates were done for each assay and metal concentrations, data are expressed as arithmetic mean \pm standard error. The Student's two-tailed t-test was used to evaluate the differences between non-trained and trained experimental means, with $\mathrm{P}<0.5$ being considered significant. In the single-spore cultures, the variation coefficients were determined to assess the variability degree among spores isolated from a common sporangium.

\section{RESULTS AND DISCUSSION}

The ascomycete Talaromyces helicus was isolated within a number of yeast and filamentous fungi from cocontaminated sludge (Romero et al. 2001, Romero et al.
2002). Although, T. helicus did not use biarylics like BP or DBF for growth, the fungus was able to co-metabolized these compounds. Three product types were formed, such as hydroxylated products in high amounts, more hydrophilic sugar-conjugates as well as a ring-cleavage product in lower amounts (Romero et al. 2005). This isolated T. helicus accumulated 6 BP-derivatives; in contrast, four of six other Talaromyces strains studied produced 4-hydroxy-BP as the only metabolite. Therefore, this strain was selected to develop copper and other heavy metals tolerance.

The growth rates of non- and trained fungus were initially inhibited at $150 \mathrm{ppm}$, being the no treated strains more

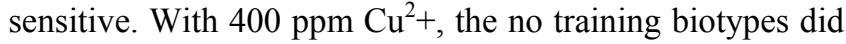
not develop, whereas the treated ones exhibited growth even at $600 \mathrm{ppm} \mathrm{Cu}^{2}+($ Figure 1).

Further assays evaluated the sensitivity of both $T$. helicus cultures to $\mathrm{Co}^{2+}, \mathrm{Pb}^{2+}$ and $\mathrm{Cd}^{2+}$, being the treated biotypes more tolerant to the heavy metals than the no trained parentals (Figure 2). No trained $T$. helicus cultures exhibited slight development with $350 \mathrm{ppm} \mathrm{Cd}$, whereas

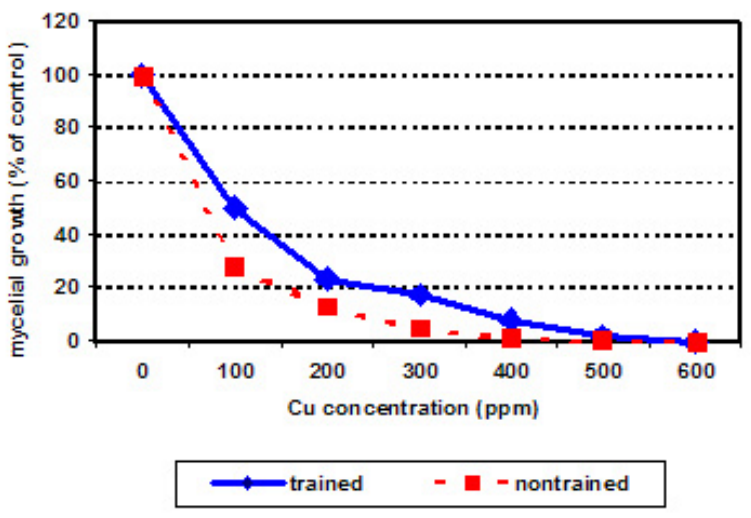

Figure 1. Cu effects on the mycelial growth on non- and trained Talaromyces helicus. 


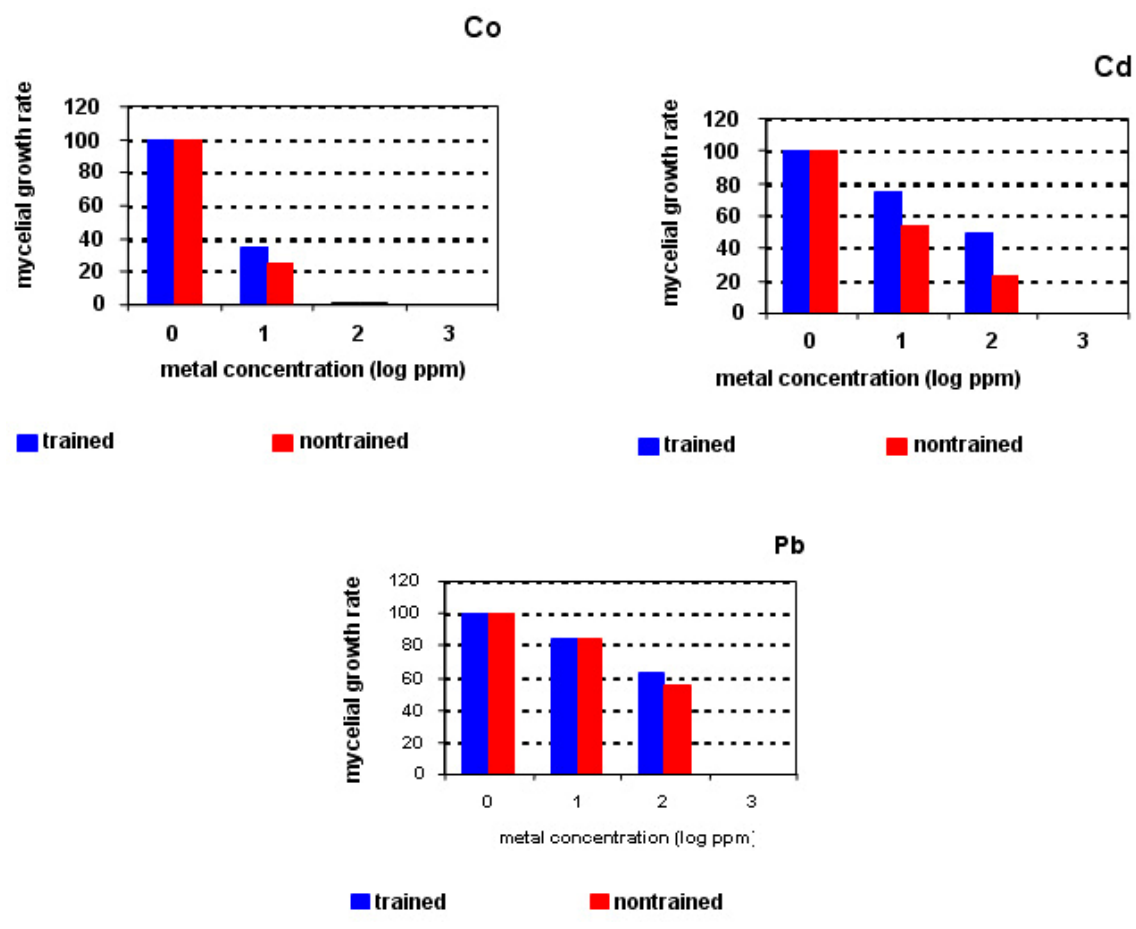

Figure 2. Co-tolerance to $\mathrm{Cd}, \mathrm{Co}$ and $\mathrm{Pb}$ of non- and trained T. helicus.

some growth occurred in Cu-treated strains with $600 \mathrm{ppm}$ $\mathrm{Cd}$. In the cobalt assays, the no treated biotypes grew till $100 \mathrm{ppm} \mathrm{Co}$; while the treated strains were tolerant to 200 ppm Co. The lead exhibited a significant lower toxicity for both culture types.

The hyphae from single-spore plates of $\mathrm{Cu}$-trained $T$. helicus grew better on $\mathrm{Cu}$-amended media, and the variation coefficients of the hyphae growth obtained from single-spore of the same sporangium of non- and $\mathrm{Cu}-$ trained fungus were significantly different. Furthermore, trained mycelia removed twice as much $\mathrm{Cu}$ from solution than those of the no trained parentals, and the amount of $\mathrm{Cu}$-removed by both cultures were correlated with the $\mathrm{Cu}$ solution levels (Table 1).

The comparative toxicity of the studied metals to non- and trained T. helicus followed the sequence $\mathrm{Co}^{2+}>\mathrm{Cd}^{2+}>\mathrm{Cu}^{2+}$ $>\mathrm{Pb}^{2+}$, but their relative toxicities were independent of the ion sizes and membrane penetration, as their no hydrated ionic radii were $0.069,0.072,0.114$ and 0.072 , respectively (Atlas and Unterman, 1999). Therefore, other mechanisms were acquired by the fungus, as a variety of interactions between fungi and ions had been proposed (Ariff et al. 1999; Pascoal and Cássio, 2004).

This fungus produced large amounts of BP-metabolites, hydroxylated ones, sugar conjugates and a cleavage product, similarly to Penicillium canescens (Hammer et al. 2001), Debaryomyces vanrijiae (Lange et al. 1998), Paecilomyces lilacinus (Gesell et al. 2001) and Trichosporon strains (Sietmann et al. 2002). This conspicuous potential was considered to select the strain for further assays.

The Cu-adaptation and the co-tolerance to other heavy metals in T. helicus is a remarkable data, as biosorption of other ions but not co-tolerance had been reported among filamentous fungi (Yan and Viraraghavan, 2000; Borghouts et al. 2001; Massaccesi et al. 2002). A noteworthy result was also the mycelia responses from $\mathrm{Cu}$-trained spores derived from the same sporangium that tolerated higher copper levels.

The impact of metals on wild soil communities had been examined on phenanthrene (Maslin and Maier, 2000), naphthalene (Sandrin et al. 2000) and phenol biotransformation (Nakamura and Sawada, 2000). These studies pointed out those metals affected adversely to no degrading members of the consortium that play a vital but indirect role in the biodegradation processes.

Some studies investigated the impact of various metals on the bioremediation of a single organic compound. Interestingly, metals combinations were less toxic than single ones, and co tolerance development indicated that the cellular mechanisms that conferred resistance were nonspecific, so the microbiota isolated from co-contaminated environments could exhibited resistance to more than one ions, consequently co-tolerance may be a common natural response (Gadd and Sayer, 2000; Amor et al. 2001).

The mechanisms by which metals inhibit the biodegradation vary with the composition and complexity 
of the system under study and include both physiological and ecological components.

In conclusion, the T. helicus resistance to heavy metals suggested that the co-tolerance and efficient biarilic transformation were acquired in nature. The issue of cocontamination is a serious one, therefore, the training of fungal strains to degradate both pollutants are a valuable environmental technology for the detoxification of cocontaminated habitats, by bioaugmentation strategy (Roane et al. 2001).

\section{REFERENCES}

AMOR, L.; KENNES, C. and VEIGA, M.C. Kinetics of inhibition in the biodegradation of monoaromatic hydrocarbons in presence of heavy metals. Bioresources and Technology, 2001, vol. 78, no. 1, p. 181-185.

ARIFF, A.B.; MEL, M.; HASAN, M.A. and KARIM, M.I.A. The kinetics and mechanism of lead (II) biosorption by powderized Rhizopus oligosporus. World Journal of Microbiology and Biotechnology, 1999, vol. 15, no. 2, p. 255-260.

ATLAS, R.M. and UNTERMAN, R. Bioremediation. In: ATLAS, R.M. and UNTERMMAN, R. eds. Industrial microbiology and biotechnology. Washington, D.C., American Society for Microbiology (ASM) Press, $2^{\text {nd }}$ ed., 1999, p. 666-681.

BORGHOUTS, C.; WERNER, A.; ELTHON, T. and OSIEWACZ, H.D. Copper-modulated gene expression and senescence in the filamentous fungus Podospora anserina. Molecular and Cellular Biology, 2001, vol. 21, no. 2, p. 390-399.

GADD, G.M. and SAYER, G.M. Fungal transformation of metals and metalloids. In: LOVLEY, D.R. ed. Enviornmental microbe-metal interactions. Washington, D.C., American Society for Microbiology (ASM) Press, 2000, p. 237-256.

GESELL, M.; HAMMER, E.; SPECHT, M.; FRANCKE, W. and SCHAUER, F. Biotransformation of biphenyl by Paecilomyces lilacinus and characterization of ring cleavage products. Applied and Environmental Microbiology, 2001, vol. 67, no. 6, p. 1551-1557.

HAMMER, E. and SCHAUER, F. Fungal hydroxylation of dibenzofuran. Mycological Research, 1997, vol. 101, no. 2, p. $433-436$.

HAMMER, E.; SCHOEFER, L.; SCHÄFER, A.; HUNDT, K. and SCHAUER, F. Formation of glucoside conjugates during biotransformation of dibenzofuran by Penicillium canescens. Applied Microbiology and Biotechnology, 2001, vol. 57, no. 2, p. 390-394.
JIN, P.K. and BHATTACHARYA, S.K. Anaerobic removal of pentachlorophenol in presence of zinc. Journal of Environmental Engineering, 1996, vol. 122, no. 3, p. 590-598.

JONIOH, V.; OBBARD, J.P. and STANFORTH, R.R. Impact of treatment additives used to reduce lead solubility and microbial toxicity in contaminated soils. In: LEESON, A. and ALLEMAN, B.C., eds. Bioremediation of Metals and Inorganic Compounds. Columbus, Battelle Press, 1999, p. 7-12.

KAMASHWARAN, S.R. and CRAWFORD, D.L. Anaerobic biodegradation of pentachlorophenol in mixtures containing cadmium by two physiologically distinct microbial enrichment cultures. Journal of Industrial Microbiology and Biotechnology, 2001, vol. 27, no. 1, p. 11-17.

KONG, I.C. Metal toxicity on the dechlorination of monochlorophenols in fresh and acclimated anaerobic sediment slurries. Water Science and Technology, 1998, vol. 38 , no. 1 , p. 143-150.

LANGE, J.; HAMMER, E.; SPECHT, M.; FRANCKE, W. and SCHAUER, F. Biodegradation of biphenyl by the ascomycetous yeast Debaryomyces vanrijiae. Applied Microbiology and Biotechnology, 1998, vol. 50, p. 364368.

LIU, C.H.; JAY, J.A. and FORD, T.E. Evaluation of environmental effects on metal transport from capped contaminated sediment under conditions of submarine groundwater discharge. Environmental Science and Technology, 2001, vol. 35, no. 11, p. 4549-4555.

MAJUMDAR, P.; BANDYOPADHYAY, S. and BHATTACHARYA, S.K. Effects of heavy metals on the biodegradation of organic compounds. In: HINCHEE, R.E., ed. Applied biotechnology for site remediation. Boca Raton, FL, Lewis Publishers, 1999, p. 354-359.

MALAKUL, P.; SRINIVASAN, K.R. and WANG, H.Y. Metal toxicity reduction in naphthalene biodegradation by use of metal chelating adsorbents. Applied Microbiology and Biotechnology, 1998, vol. 64, no. 11, p. 4610-4613.

MASLIN, P. and MAIER, R.M. Rhamnolipid enhanced mineralization of phenanthrene in organic metal cocontaminated soils. Bioremediation Journal, 2000, vol. 4, no. 2, p. 295-308.

MASSACCESI, G.; ROMERO, M.C.; CAZAU, M.C. and BUCSINSZKY, A.M. Cadmium removal capacities of filamentous soil fungi isolated from industrially polluted sediments, in La Plata (Argentina). World Journal of Microbiology and Biotechnology, 2002, vol. 18, no. 4, p. 817-820. 
NAKAMURA, Y. and SAWADA, T. Biodegradation of phenol in the presence of heavy metals. Journal of Chemistry Technology and Biotechnology, 2000, vol. 75, no. 1, p. 137-142.

NEILSON, J.W. and MAIER, R.M. Biological techniques for measuring organic and metal contaminants in environmental samples. In: CLAPP, C.E.; HAYES, M.H.B.; SENESI, N.; BLOOM, P.R. and JARDINE, P.M. eds. Humic Substances and Chemical Contaminants. Madison, WI, Soil Science Society of America, 2001, p. 255-273.

NIES, D.H. Microbial heavy metal resistance. Applied Microbiology and Biotechnology, 1999, vol. 64, no. 11, p. 4610-4613.

PASCOAL, C. and CÁSSIO, F. Contribution of fungi and bacteria to leaf litter decomposition in a polluted river. Applied and Environmental Microbiology, 2004, vol. 70, no. 12 , p. $5266-5273$.

RICART, M.T.; HANSEN, H.K.; CAMESELLE, C. and LEMA, J.M. Electrochemical treatment of a polluted sludge: different methods and conditions for manganese removal. Separation Science and Technology, 2004, vol. 9, no. 10, p. 3679-3689.

ROANE, T.M.; JOSEPHSON, K.L. and PEPPER, I.L. Dual-bioaugmentation strategy to enhance remediation of co contaminated soil. Applied and Environmental Microbiology, 2001, vol. 67, no. 10, p. 3208-3215.

ROANE, T.M.; MILLER, R.M. and PEPPER, I.L. Microbial remediation of metals. In: CRAWFORD, R.L. and CRAWFORD, D.L., eds. Bioremediation: Principles and Applications. Cambridge, UK, Cambridge University Press, 1996, p. 312-340.

ROMERO, M.C.; HAMMER, E.; HANSCHKE, R.; ARAMBARRI, A.M. and SCHAUER, F. Biotransformation of biphenyl by filamentous fungus Talaromyces helicus. World Journal of Microbiology and Biotechnology, 2005, vol. 21, no. 1, p. 101-106.

ROMERO, M.C.; SALVIOLI, M.L.; CAZAU, M.C. and ARAMBARRI, A.M. Pyrene degradation by filamentous soil fungi and yeast species. Environmental Pollution, 2002, vol. 117 , no. 1 , p. 159-163.

ROMERO, M.C.; HAMMER, E.; CAZAU, M.C. and ARAMBARRI, A.M. Selection of autochthonous yeast strains able to degrade biphenyl. World Journal of Microbiology and Biotechnology, 2001, vol. 17, no. 6, p. 591-594.

SANDRIN, T.R. and MAIER, R.M. Impact of metals on the biodegradation of organic pollutants. Environmental and Health Perspective, 2003, vol. 111, no. 4, p. 10931101.
SANDRIN, T.R. and MAIER, R.M. Effect of $\mathrm{pH}$ on cadmium toxicity, speciation and accumulation during naphthalene biodegradation. Environmental Toxicology and Chemistry, 2002, vol. 21, no. 5, p. 2075-2079.

SANDRIN, T.R.; CHECH, A.M. and MAIER, R.M. A rhamnolipid biosurfactant reduces cadmium toxicity during biodegradation of naphthalene. Applied and Environmental Microbiology, 2000, vol. 66, no. 10, p. 4585-4588.

SIETMANN, R.; HAMMER, E. and SCHAUER, F. Biotransformation of biarylic compounds by yeasts of the genus Trichosporon. Systematic and Applied Microbiology, 2002, vol. 25, no. 2, p. 332-339.

YAN, G. and VIRARAGHAVAN, T. Effect of pretreatment on the bioadsorbents of HM on Mucor rouscii. Water Research, 2000, vol. 26, no. 1, p. 119-123.

ZOUMIS, T.; SCHMIDT, A.; GRIGOROVA, L. and CALMANO, W. Contaminants in sediments: remobilization and demobilization. The Science of the Total Environment, 2001, vol. 266, no. 1, p. 195-202. 